\title{
ASSESSMENT OF THE LIFE EXPERIENCES OF VISUALLY IMPAIRED ADULTS IN THE EMPANGENI REGION OF KWAZULU
}

\author{
B.M. Zungu
}

\section{INTRODUCTION}

Vision is essential for most employment and is necessary in countless experiences that make life enjoyable and meaningful. There are many blind people who humiliatingly, are illiterate because they cannot sign their names, even though they may have high educational qualifications acquired before the onset of their disability. Some blind people can be found at street corners of every town begging for money in order to meet their fmancial needs.

Blindness is a threatening and disabling experience which is viewed generally as contributing to grave problems for the blind person, his family and society. The great concern is that visual impairment is a common disability in developing countries and especially so in rural communities. Because of inaccessibility and inadequacy of health services in such communities, the people often lack motivation to seek help until the disease is very far advanced. Conditions such as chronic simple glaucoma, cataract, injuries, severe infection and burns are often neglected.

In South Africa, very little information is available regarding the etiology and extent of visual impairment, and the availability of services to the visually impaired in different communities and different areas (McKendrick, 1988).

It is important to note that visual impairment is mostly caused by preventable as well as curable conditions. This indicates that prevention and treatment services are to operate concurrently with rehabilitative services.

\section{PURPOSE OF STUDY}

The purpose of this article is to discuss the findings of a study undertaken by the author, in which the life experiences of daily living of blind adults, as influenced

\section{Abstract}

The purpose of the study was to assess how visual impairment influenced the experiences of daily living of blind adults in a rural community in KwaZulu.

Information was elicited through semi-structured interviews with 16 people (eight men and eight women) between the ages of 21 and 55 years who had been visually impaired from one to more than 20 years. Such visual impaiment ranged from inability to perform some of the activities that require the use of eyesight to inability to see at all.

Certain factors such as reactions to loss of sight problems experienced by visually impaired persons, adjustment and coping strategies were identified.

by visual impairment, were elicited and interpreted from sixteen persons who had become visually impaired at various stages of development.

Essentially, the research question became:-

"How has the experience of loss of sight affected the daily lives of blind adults living in a nural community in KwaZulu?"

\section{DEFINITION OF TERMS}

In this study, activities of daily living are all those activities needed for individual survival such as eating, dressing, washing, walking unaided, etc. Life experiences are defined as positive or negative day-to-day events or occurrences encountered by a person with visual impairment.
A visually impaired person is an individual whose visual loss caused inability to perform some or all activities requiring eyesight; this definition includes the partially sighted as well as totally blind individuals and the term is subjectively rather than legally defined.

\section{METHODOLOGY}

In order to clarify the question of how visual impairment affected experiences in daily living of blind adults in a rural community in KwaZulu, a descriptive survey using semi-structured interviews was used. Table 1 summarises points covered during interviews.

Table 1
Semi-atructured Intervlew gulde
The following aspects of experience/dally
living were explored:-
1. The development of blindness and cure
sought.
2. Client's subjective reaction to blindness.
3. Others' reaction to blindness (family,
relatives, friends and community).
4. Problems oncountered.
5. Coping strategies.
6. Help needed.
7. Socio-demographic data e.g. age,
marital status, sex, income including
details of Disability Grants.
8. Attendances at rehabilitation
programmes and support from health
professionals e.g. guidance in direction
to appropriate services.

\section{SAMPLE}

The sixteen persons (eight men and eight women) who constituted the convenience sample for this study were between the ages of 21 and 55 years and had been visually impaired from one to more than 20 years.

Random sampling was not possible as no sampling frame is available. Visually impaired individuals are scattered widely 
and there is no central or regional register of persons with visual loss. Initially an attempt at obtaining the sample was made by checking statistics from a hospital out-patient department and clinic attendance records; this was not possible because of inadequately kept records. Patients with eye problems are referred to medical practitioners or ophthalmologists without being entered into relevant records and this gives a false impression that there are not many people with eye problems in the area.

Because it was not possible to obtain the sample from hospital and clinic records, convenience sampling was undertaken by advertising. The Clinic Professional Nurse-in-charge distributed letters to the principals of all primary schools in the area. She requested them to ask pupils to give messages to their parents for all partially sighted and blind adults to visit the clinic on a stipulated day and time. This was done on two occasions and it proved to be successful, uncomplicated and economically viable. The respondents were then later visited at their homes for interviews.

\section{PROBLEMS OF A CONVENIENCE SAMPLE}

The fact that the sample is a non-random type is a major constraint since it is not truly representative of the population of the Empangeni rural community. It is possible that a particularly well-adjusted group of people, proud of the way they had coped with disability, volunteered to be interviewed. It does not allow generalization, but allows insight and understanding of life experiences of blind adults able to attend a rural clinic.

\section{METHOD OF OBTAINING DATA}

Interviews were conducted privately with the family members of the interviewees not present. The researcher carried out all interviews herself and all interviews were conducted in Zulu.

Permission to conduct interviews was obtained from the respondents and their family members. Some interviews were tape recorded to save time.

The interviews were viewed as a collaborative effort between the informant and the investigator. A semi-structured informal interview was a method of choice for this study because it helped the respondents to remember facts accurately in a relaxed unhurried atmosphere. Clarification and recording of questions was made as necessary to meet the understanding of the respondents.

\section{FINDINGS}

Based on their description of what caused their eye problems, respondents were categorized into six broad diagnostic groups. Table 2 outlines the causes of blindness as perceived by the respondents.

\begin{tabular}{|c|c|}
\hline \multicolumn{2}{|c|}{$\begin{array}{c}\text { Table } 2 \\
\text { Causes of blindness }\end{array}$} \\
\hline Cause & $\begin{array}{l}\text { Number of } \\
\text { Respondents }\end{array}$ \\
\hline Measles & 6 \\
\hline Glaucoma & 3 \\
\hline Pink eye & 2 \\
\hline Trauma & 2 \\
\hline Cataract & 1 \\
\hline Not known & 2 \\
\hline TOTAL & 16 \\
\hline
\end{tabular}

Most respondents explained the causes of blindness by describing symptoms with which they presented. The symptoms were later interpreted as a particular condition by the investigator. Two respondents found it difficult to clearly explain what their problems were. Most probably this can be attributed to the fact that blindness occurred during childhood, at eight and ten years respectively. Table 3 outlines the age at which blindness occurred.

\begin{tabular}{|l|l|}
\hline \multicolumn{2}{|c|}{ Table 3} \\
\hline \multicolumn{2}{|c|}{ Age at which blindneas occurred } \\
\hline $1-9$ & $\begin{array}{c}\text { Number of } \\
\text { Reapondents }\end{array}$ \\
\hline $10-19$ & 8 \\
$20-29$ & 2 \\
$20-39$ & 1 \\
$40-49$ & 2 \\
$50-55$ & 2 \\
TOTAL & 1 \\
\hline
\end{tabular}

Out of sixteen respondents, ten became blind during childhood (between the age of 01 - 15 years). This was due to preventable causes, the main one of which was measles.

\section{REACTIONS TO LOSS OF VISION}

The question asked of the respondents was "How did you feel after losing sight?" Men and women had similar reactions. Married males and females feared being considered useless by their partners.
Unmarried males and females feared losing their partners and the possibility of not getting married.

The only difference was that married males had a strong fear of feeling useless, since they are heads of the family.

Respondents who became blind during adult life stated that it was heart breaking. They were depressed, lost hope, felt useless and helpless. One male respondent stated, "I wished to die and decided on committing suicide since I felt useless and helpless as a man when realizing that my wife must now be a bread winner. I realized that I am going to be a burden to my family." He explained further that these feelings gradually subsided because of the support and respect shown by his family, especially the wife.

Some respondents experienced a gradual loss of vision. Their reaction differed from those who had sudden loss of vision. They explained that they hoped the lost vision would be recovered, as they continued seeking medical advice and to have spectacles prescribed and surgical treatment performed.

One female respondent stated that she visited three hospitals. In one hospital a lens extraction was performed but she totally lost sight after this procedure. She explained further that the doctors eventually told her that her visual deterioration was not caused by a cataract, but did not tell her what the cause was. She stated: "I then sought for other cures from traditional healers and $a$ Zionist." According to her statement, this was all in vain. She had paid three cows to three different traditional healers, who had faithfully promised that they would restore her sight. The Zionist however, made no charges, but expected her to come with two candles and twenty cents for the prayer every time she visited her. She pointed out that she was sad and eventually lost hope, and was frustrated to realize that all efforts made were in vain. She then decided to stay at home without cure.

Respondents who became visually impaired during childhood experienced negative reaction caused by restricted physical mobility which made them unable to join playmates and to commence schooling. One respondent recalled, "I became frustrated and felt lonely when my friends visited me. They stayed with me for a few hours in the house and thereafter left me for playing."

When asked about how their family members felt, respondents said that they 
experienced similar reactions. They appeared depressed, frustrated and engaged in deep thought about getting the best cure. Respondents further explained that family reactions were shown by trying to do everything for the disabled who viewed this as over-protection. The protection seemed an obstacle towards adjustment and coping, since they were not only protected from potential injuries but from relearning how to perform activities of daily living such as playing, cooking, bathing and cleaning.

Respondents who lost vision during childhood experienced over-protection from their parents, who would not permit them to go playing with their friends. One respondent recalled his mother saying: "Leave him alone, don't you know that he cannot see and can be injured."

Analysis of the interviews revealed that the duration of the grieving process varied from individual to individual. This is attributed to such factors as individual problems, age of onset, social support and coping strategies.

\section{PROBLEMS EXPERIENCED}

The study revealed four factors as the major problems experienced by the respondents. These are summarised in Table 5.

The respondents pointed out that the mobility problem was the most serious one which caused loss of free movement. They explained that restricted physical mobility created other problems for them such as social isolation, inability to carry out activities of daily living, especially cooking and gardening. Some respondents described mobility problems as causing loss of personal independence, since they had to request assistance from family members, relatives or friends if they needed to visit important places such as shopping centres and places of entertainment.

Unemployment and financial insecurity was viewed by most respondents as great problems. Male respondents emphasized that the mobility problem prevents them from getting employment since they cannot move freely without help and this makes them unable to work and support their families. They emphasized further that change of roles such as a wife having to support the family and acting as a breadwinner is frustrating and contributes to a sense of being less than a man. They expressed a strong need to educate their children and to maintain a reasonable standard of living like other people.
Table 4 outlines strategies by which the respondents met their fmancial needs at the time of interview.

\begin{tabular}{|l|l|}
\hline \multicolumn{2}{|c|}{$\begin{array}{c}\text { Table 4 } \\
\text { Occupation of reapondents at } \\
\text { the time of interview }\end{array}$} \\
\begin{tabular}{|l|l|}
\hline \multicolumn{1}{|c|}{ Occupation } & \multicolumn{1}{c|}{ Number of } \\
Respondents
\end{tabular} \\
\hline $\begin{array}{l}\text { Housekeeping } \\
\text { Craft Work } \\
\text { Car welding } \\
\text { Herbalist and Zionist } \\
\text { healor } \\
\text { None } \\
\text { TOTAL }\end{array}$ & 5 \\
\hline
\end{tabular}

\section{Table 5
Summary of problems experienced by viaually Impalred pereona}

a) Restriction of physical mobility.

b) Social isolation and segregation which includes emotional frustration, loss of personal independence, and a sense of being less than a whole person.

c) Economic insecurity.

d) Inability to identify monies (coins and notes).

One female respondent was engaged in knitting jerseys and selling them. One male respondent was engaged in car welding jointly with his brother.

Out of the sixteen respondents, one male presented a very different picture than the others. He was fifty-five years old, inactive, less motivated and lived alone in a dilapidated house and could hardly make a fire for himself. He had no source of income and no disability grant. He was supported by his brother's sons. He explained that he had never been employed. He used to look after his brother's stock and was then given some money. His brother died five years ago. He further stated that he would like to be institutionalised since he felt unsafe.

Only 10 out of sixteen respondents had a disability grant although technically all would be entitled to such a grant. Ten respondents receiving a disability grant felt it is not enough since they have families to support and educate. A disability grant is currently R400 paid every second month.

One female respondent with no disability grant was fully supported by her sons and daughters. She was responsible for most house activities.

All respondents stated that they experience a problem of not being able to see their friends or any family member. All respondents expressed a problem of identifying money. They explained that they had to develop skills in identifying various coins and notes, and this needed development of a sense of touch.

Those who were self-employed pointed out that quite often they were cheated by people, and they requested assistance from a family member or friend every time they went out selling.

Most respondents proved to have adjusted and coped well to visual impairment without formal rehabilitation. The question of how they adjusted and coped with visual impairment was covered during the interview.

\section{ADJUSTMENT AND COPING STRATEGIES}

Factors that helped respondents toward the development of adjustment and coping strategies emanated from the data.

As summarized in Table 6 problems encountered after loss of sight were highlighted by fifteen respondents as the most important motivating factor that contributed to their coping. They pointed out that the problems they encountered motivated them to decide on learning new ways of doing things or to adapt present ways so as to be able to carry out normal activities of daily living.

Table 6
Summary of factora that contrlbuted to
adjustment and coplng
a) Problems encountered acted as a
motivation.
b) Social support from:
the peer group, regarded as the most
influential especially in children.
the family, provided it assists the
visually impaired member to be
independent as much as possible and
avoids over-protection.
c) Comparison with others who have
normal vision, which motivated the
visually impaired to prove they could do
as well.
d) Talking to other visually impaired
people to get advice and ideas.

The respondents were requested to explain how they managed to cope with visual impairment, since they appeared to have adjusted rather well. They described the process of adjustment as a difficult one that takes time. What actually motivated them were the problems they encountered after loss of sight. Following the realization of the loss and concomitant with the 
implications of the loss, respondents reacted both overtly and covertly to their decreased or lost vision. Depression, self-pity and withdrawal were common. In addition there were multiple fears during this time such as fears about going out alone, fears about whether they could cope and fears about what the future held for them.

At some point subsequent to the initial reaction to the visual impairment, respondents made a conscious or unconscious decision to adjust to the impairment.

In conjunction with this decision new ways of doing things were learned or present ways were adapted so as to be able to carry out normal activities of daily living. What also acted as a motivation towards performance of the activities of daily living was the comparison with sighted people. The female respondents maintained that they learned to cook, wash and iron clothing for the family because they wanted to prove that they could do even better than the sighted people. The problem that they initially had to cope with was mobility, since the opinion they have is that mobility is the vital skill that assists in over-coming most problems.

Respondents were requested to state how they learned mobility skills on their own, following vision loss. The description they gave was an interesting one. Some respondents stated that initially they became confused and disoriented even in familiar surroundings, and this was caused by being afraid of what could be in the way such as obstacles inside and outside the house. After the initial stage, they decided to use sticks as mobility aids. Nobody introduced the use of sticks to them; it was entirely their own idea. Sticks facilitate the functioning of the sense of touch/feeling and are used for identifying objects that can be used as landmarks in any direction when walking. The stick is for feeling/touching front, right and left side and in this way, the objects that are touched by the stick are the landmarks. The objects could be the furniture in the house or the doors. When outside the house, other houses acted as landmarks; subjects counted the number of houses they passed in order to get to a specific point. The type of the surface under foot, whether even or uneven, and rough soil or fme soil or tarred road are good landmarks identified by the stick and feet. Eventually respondents learnt how to walk freely. What was highlighted in the interviews was that a sense of touch/feeling must gradually become sensitive to assist in mobility.

The respondents pointed out that the most dangerous area is walking on the road because of traffic. They explained that they must be able to note the distance of the oncoming and the off-going car through hearing of sounds. Most of them maintained that they have not developed this skill and therefore are fearful of going to town or walking on the road without assistance.

When questioned about the use of guide dogs, no respondent saw the need for guide dogs. Respondent 0 said, "I cannot imagine a dog showing me the way to whatever place I want to go to". Most of them had no idea about guide dogs at all.

The respondents pointed out that at the outset, they were awkward in performing activities of daily living such as cooking cleaning and washing. Women felt that inability to cook was most frustrating Respondent B learned cooking because she was at times left alone without food for the whole day, or school children were to prepare for her. She felt she was a burden on school children who at times arrived late at school because of her dependence. She recalled, "I made a fire, attempted to cook porridge (uphuthu), it got bumt, because of too much fire. I tried to boil an egg, it also got bumt because of too much fire and little water. I never stopped trying, eventually I leamed to cook for the whole family". She emphasised that, as a visually impaired person you never stop encountering new problems in life. She explained further that her ability to move around in the house for cooking made her face another problem of getting out of the home environment to collect firewood from the nearby forest and water from the well. She maintained that she felt obliged to learn new skills. She decided to do something about her dependence and accepted the challenge. She was unmarried and had a boyfriend during the onset of blindness. She was dependent on her parents for everything that needed money. After realising that she was totally blind, she felt unhappy when recalling the money that her parents have spent trying to get cures for her. She then decided to do something that would allow her to get money and become independent somehow. She recalled, "I requested my sister who was good at knitting jerseys, to teach me knitting. I had no money for buying wool, I had to undo old jerseys to get the wool for leaming. This was a success, I am still knitting jerseys, and getting money out of them. I have bought myself goats out of the money I have made". She explained further that later she was referred by her uncle to a workshop in Durban where she refined her knitting skills.

Male respondents described how they learned to be mobile by cleaning the home yard and doing some gardening.

All respondents felt that contact with other visually impaired persons made them realise that such persons are capable of moving freely and performing most activities of daily living. They further maintained that advice and ideas from other visually impaired persons are acceptable and motivating.

Those who became blind during childhood were assisted by their play peers.

The family was cited as most influential in adjusting, provided over-protection is avoided. Respondents mentioned that though the family is supporting, it tends to over-protect the blind person because they think he may be injured. To avoid this behaviour, the respondents had to "steal" activities until their skills were adequate to be accepted by the family members.

\section{THINGS THAT DID NOT HELP ADJUSTMENT}

Respondents also explained things that they experienced as most difficult for them in learning how to cope with visual impairment.

As summarised in Table 7 , social isolation in terms of lack of someone with whom to talk and share mutual experiences was cited as a major factor that hindered adjustment to visual impairment.

Table 7
Factore which hindered coping
a) Social isolation.
b) Lack of information, for instance, about
the process of obtaining a disability
grant.
c) Being labelled as "blind" and being
pitied.
d) Negative attitudes from the community,
for instance, denying access and other
rights.
e) People who had no work or property
before losing their sight found it more
difficult to cope.
Lack of guidance from health workers.

All respondents maintained that being labelled and named as a "blind person" (Impumputhe) interferes with their free mixing with community members. One female respondent stated "I am not a 
blind person, but I am a person who has become blind".

Perceived unhelpful/negative behaviour of other people was viewed as discouraging by all respondents. It was mentioned that community members view visually impaired people as objects to be kept indoors or institutionalised and not be seen moving around amongst those with normal sight. Respondents pointed out that this negative attitude was mostly displayed when they had to take transport for shopping, or when visiting the hospital for their illness. One female respondent recalled, "I wept when one man shouted at me, reminding me that I am blind, I must stay at home and stop using buses since I am blocking their way because of my blindness, there is no transport for blind people, all blind people are at their homes or institutionalised".

The respondents pointed out that the community attitude of feeling pity for the blind person hinders the adjustment process and facilitates dependence.

People who had no work or property before losing their sight found it more difficult to cope (such as the male respondent who had never been employed and eventually became inactive after losing sight).

Some respondents mentioned lack of guidance from health workers as an obstacle toward coping. They explained that if the loss of vision is gradual and if professional workers have an awareness that there is no cure, the possibility of permanent loss of vision should be stated.

\section{DISCUSSION}

Roy's adaptation model of nursing helped the author clarify the above fmdings. (Roy 1984).

"Nursing's goal is to promote patient's adaptation in all four adaptive modes: self-concept, role mastery, basic physiological needs, and interdependence during health and illness" (Roy 1984 quoted by Fawcett, 1984:255).

The respondents regarded the problems encountered as environmental stimuli motivating them to adapt positively. They develop coping strategies independently with no professional rehabilitation. Strategies for coping with visual impairment highlighted by respondents may be grouped into psychological, social and environmental (Allen 1989).

The results of the study support the notion that there is a gradual process of adjusting to a visual impairment, which consists of an impact, implications of the loss and reactions to the loss, (Hollins 1989; Allen, 1989).

Some of the causes of blindness such as measles, pink eye and trauma possibly could have been prevented, and a cataract could have been identified early and treated as pointed out by Perry and Tullo, (1990).

The study has certain implications for nursing. By examining life experiences of visually impaired persons, nurses gain knowledge regarding client's problems, reasons for these problems and deliver more effective eye care in clinics, hospitals, homes and rehabilitation centres. Rehabilitation nurses, community health nurses and community health workers may better assist visually impaired clients in coping with adaptive demands of visual impairment, and where uncertainty about the future exists, nursing could provide support as the client re-organizes life style.

Primary Health Care, effectively implemented, would aid the following strategies:-

a) Prevention of eye conditions such as eye infections/inflammations, measles and other preventable eye diseases.

b) Health education in order to effect rural community immunization against measles; educating parents especially mothers so that children attend clinics regularly. Nurses must be alert to identify inadequately immunized children, especially during a measles outbreak.

c) Health education relating to the nutrition of children; food rich in Vitamin A and the role of Vitamin A for the integrity of the conjunctival and corneal epithelium to be highlighted.

d) Follow-up care for patients with eye problems to be undertaken by nurses.

e) Systematic continuing education on specialised fields including ophthalmic nursing care should be undertaken to ensure primary health care nurses and health workers are kept sensitized and knowledgeable about these fields.

Further research in rural areas in KwaZulu is recommended. Important issues relate to causes of blindness, the number of visually impaired children and the professional help they get, the number of visually impaired adults, those who have adjusted as well as those who have not adjusted to their visual impairments. The information obtained may assist in motivating people to utilize available services effectively and make services accessible to the people in rural areas. It may assist health planners, health professionals, and significant members of the rural communities (chiefs and indunas) to negotiate with health planners about establishing relevant services for the visually impaired.

The community needs education to accept visually impaired individuals. Rehabilitation nurses should initiate organised campaigns to change attitudes of the community about visual impairment. The community should be educated on causes, effects and nature of the disability, potentials of people with visual impairment and their families, and the avoidance of labelling people with visual impairment. This can be initiated through various public information methods such as television programmes, sports for radio, news letters and by making representations to commumity groups.

\section{REFERENCES}

ALLEN, M.N. (1989): The Meaning of Visual Impairment to Visually Impaired Adults. Journal of Advanced Nursing. 16: 640-464.

HOLLINS, M. (1989): Understanding Blindness. An Integrative Approach. New Jersey; Lawrence and Erlbaum.

MCKENDRICK, B. (1985): Charting a National Course for Rehabilitating Newly-blind Adults. Rehabilitation in South Africa 29(1) : 2-6.

McKENDRICK, B. (1988): Community Based Rehabilitation. A New Emphasis in Responding to the Needs of Blind and Visually Disable People. IMFAMA 28: 2-4.

PERRY, J.P. \& TULLO, A.B. (1990): Care of Ophthalmic Patient. A Guide for Nurses and Health Professionals. London. Chapman and Hall.

ROY, S.C. (1984): Introduction to Nursing. An Adaptation Model. New Jersey; Prentice Hall.

BUSISIWE MAYAH ZUNGU (R.N, OPHTHALMIC NURSE, B.CUR) Department of Nursing Science University of Zululand. 